\title{
215. Electron Microscope Observation of the Motor Cell of Mimosa pudica L. II
}

\author{
On the Contents of the Central Vacuole \\ of the Motor Cell*)
}

\author{
By Hideo ToRIYama**) and Syôiti Satô***) \\ (Comm. by Tetsu Sakamura, M.J.A., Nov. 12, 1968)
}

Our previous paper (Toriyama and Satô, 1968) has presented the results of our study by electron microscopy of the effect of stimulation upon the motor cell of Mimosa pudica. We have repeatedly noticed in our series of investigations that the motor cells of this plant contain the characteristic tannin vacuole and remarkable protoplasmic components equally before and after stimulation. In the present investigation, the application of narcotics enabled us to examine the fine structure of the contents of the central vacuole of the motor cell, both before and after stimulation under diurnal conditions.

Experimental materials. The study has been carried out using the same materials as were used in the previous work (Toriyama and Satô, 1968). In order to have the materials of the motor cell of the main pulvinus free from any stimulus, the plants were, as usual, exposed to ether vapour for 25 to 30 minutes. Chiefly the tissue of the ventral half of the main pulvinus was used.

Optical microscopy. Some preliminary and complementary observations were made by the use of an optical mciroscope. The materials were fixed with Müller's fluid for 24 hours. After a complete fixation, they were thoroughly washed in running water for 10 hours. The dehydration was performed through a series of concentrations of tertiary butyl alcohol. The embedding in paraffin happened as usual. Paraffin blocks were cut 15 micra thick. The sections were then stained with a $1 \%$ methyl blue aqueous solution. In the samples made by this technique, the protoplasts of the motor cells were clearly observable (Figs. 1a and 1b). In some of these cells, indicated by asterisks, in Figs. $1 \mathrm{a}$ and $1 \mathrm{~b}$ the tannin vacuole and protoplast appeared, while in other cell, the protoplasts differed

*) This research has been supported in part by a Grant-in-Aid for Scientific Research from the Ministry of Education.

**) Biological Section, Tokyo Woman's Christian College, Tokyo.

***) Department of Biology, Japan Women's University, Tokyo. 


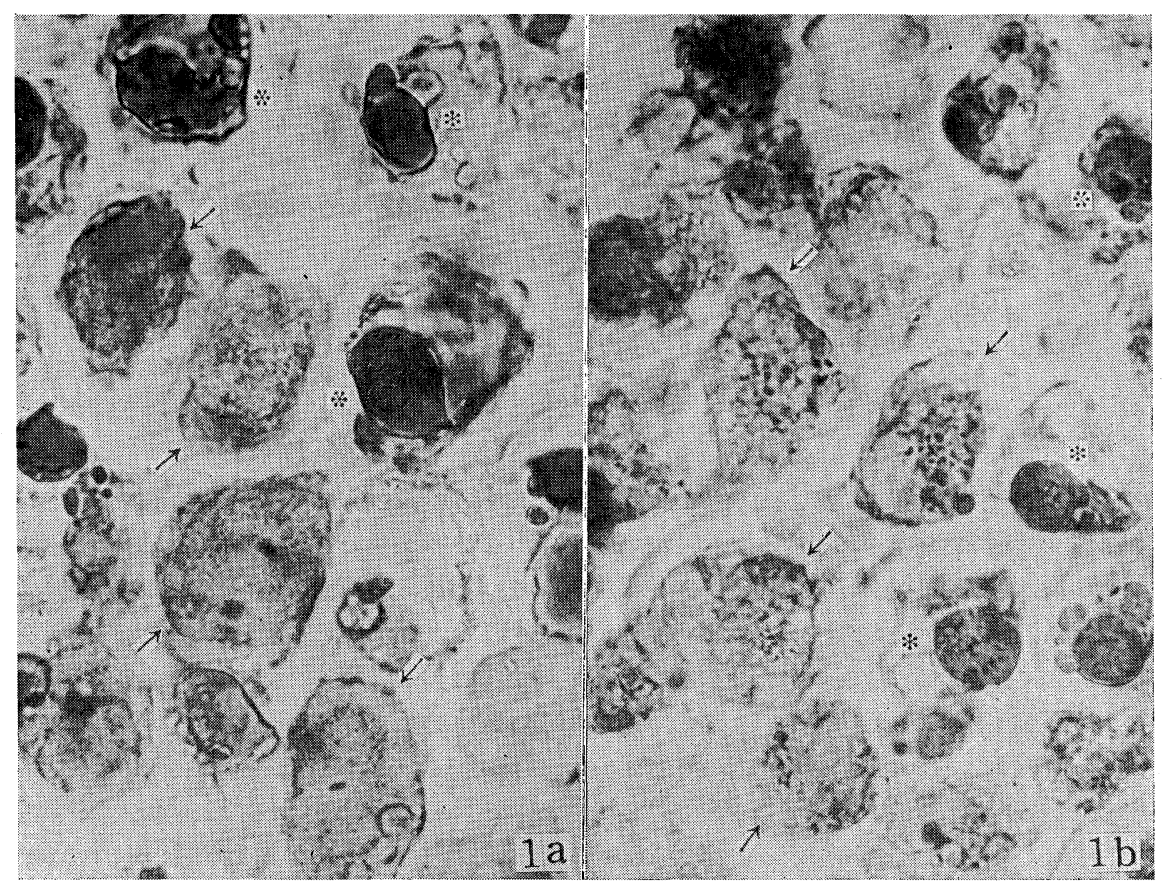

Fig. 1. Motor tissue-cells of main pulvinus of Mimosa pudica L. a: before stimulation; b: after stimulation. Asterisks indicate tannin vacuole with protoplast. Arrows indicate protoplasts $\times 800$. The above two sections were fixed with Müller's fluid and stained with $1 \%$ methyl blue.
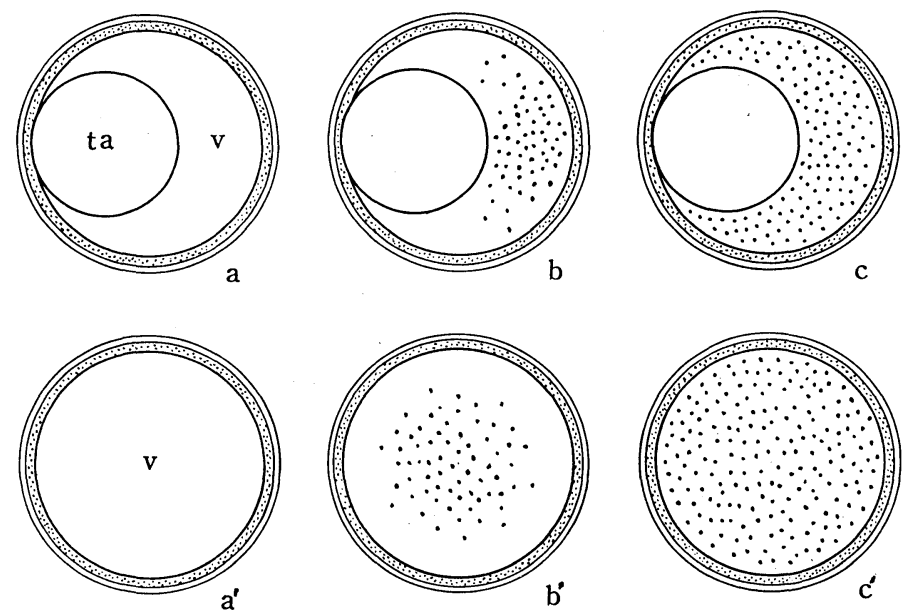

Fig. 2. Schematic figures of several types of Mimosa motor cells with tannin vacuoles. ta: tannin vacuole; v: central vacuole; dots indicate the contents (diffused fibrils) of the central vacuole. $\mathbf{a}^{\prime}, \mathrm{b}^{\prime}$, and $\mathrm{c}^{\prime}$ are on sections which do not include the tannin vacuole. 
from those in former case (shown by arrows in Figs. 1a and 1b). In the same microphotographs, the contents of the central vacuole could not be markedly discriminated from the protoplast. The shrink-

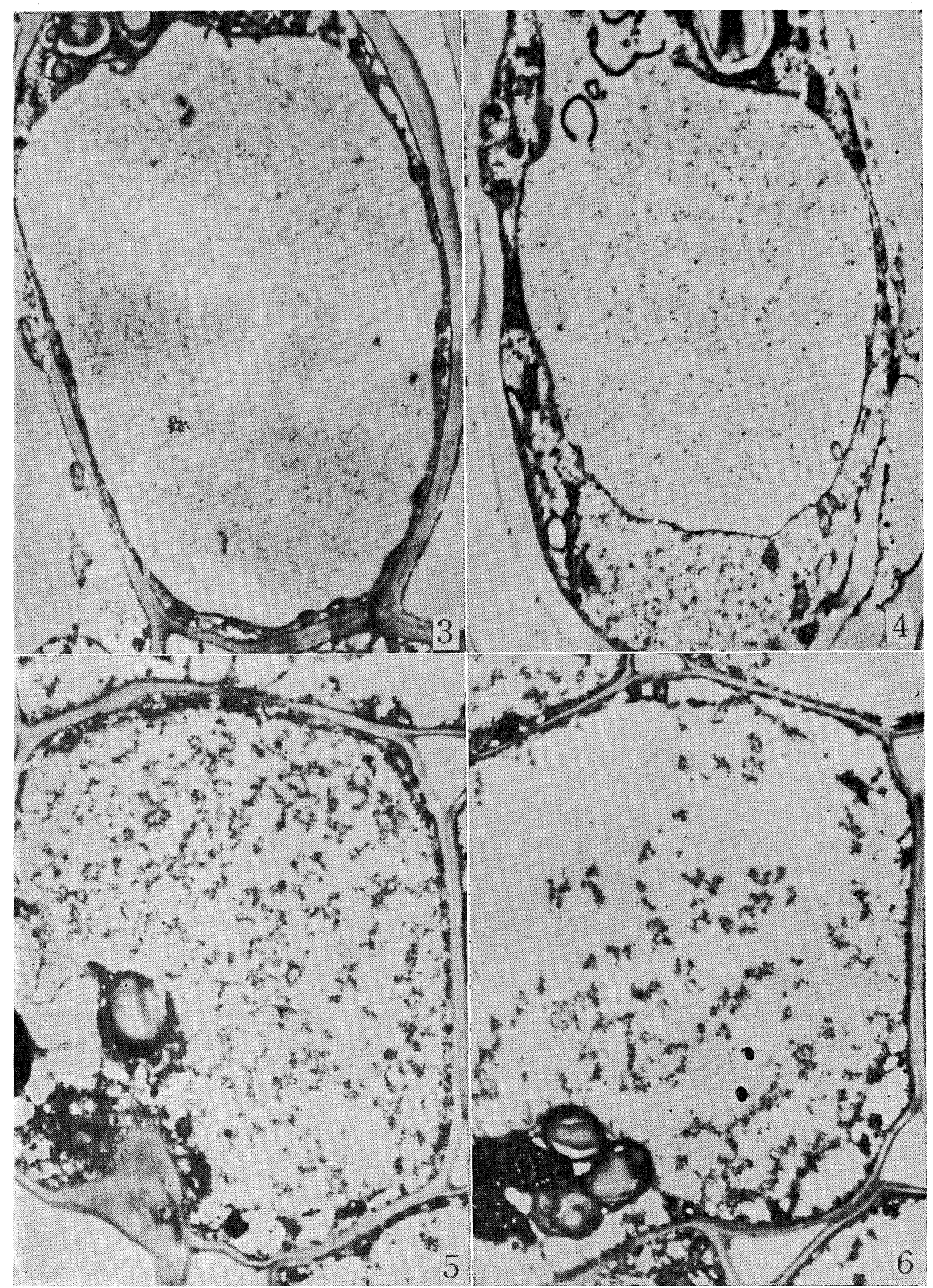

Figs. 3-6. Electron micrographs of motor cell of main pulvinus of Mimosa pudica L. $3(\times 4800), 4(\times 6400)$ before stimulation. $5(\times 5400), 6(\times$ 5400) after stimulation. All the micrographs were taken from cell materials fixed with $\mathrm{OsO}_{4}$. 
age of the protoplast was clearly visible after stimulation (Fig. 1b).

In the previous paper (1967), one of the present authors found, by the use of the Kaiser-toluidine blue technique, that there were some motor cells, which contained one tannin vacuole each, while some others did not. Further close observation made it possible to establish several types of central vacuoles of the motor cells, each containing one tannin vacuole, as is shown schematically in Fig. 2.* There were scarcely any contents of the central vacuole observable in some cells (Figs. 2a, a'), while the contents were more or less clearly visible in other cells (Figs. 2b, $b^{\prime}, c, c^{\prime}$ ).

Electron microscopy. The main pulvinus of Mimosa pudica

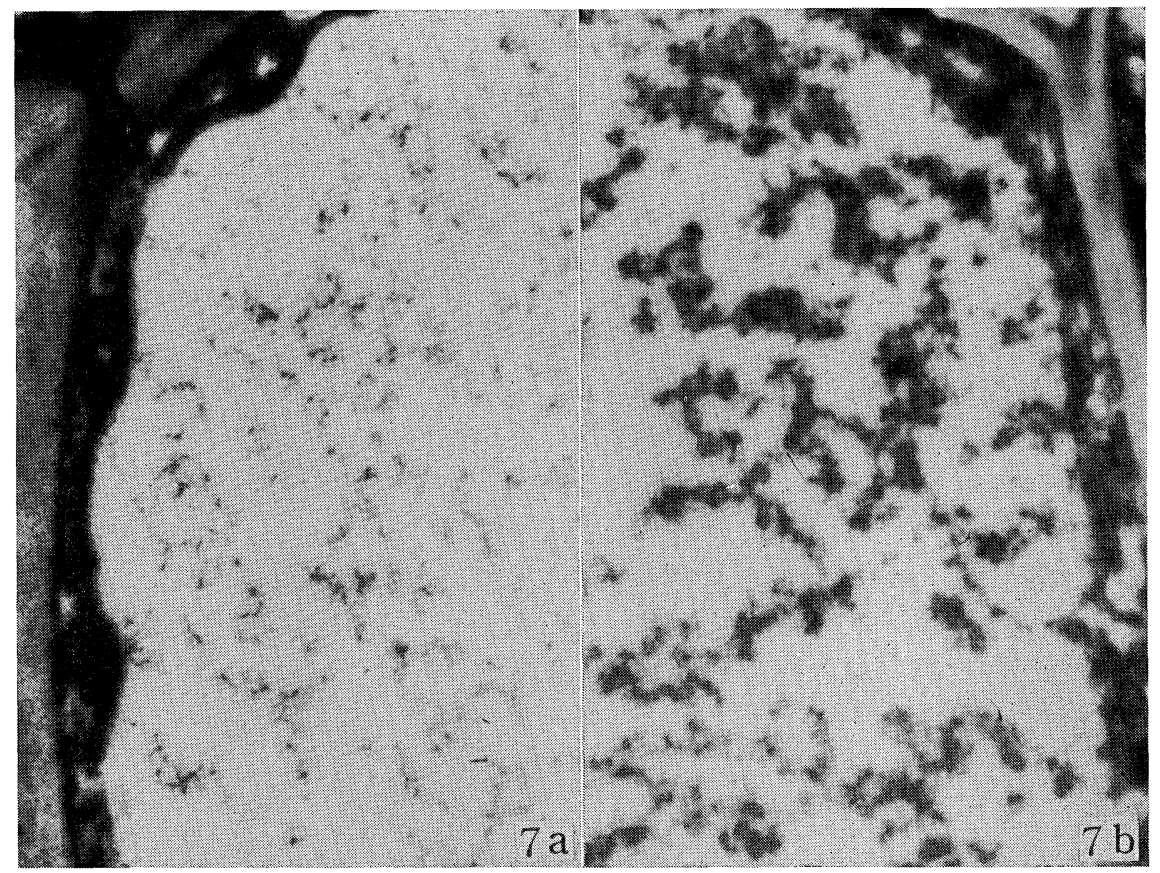

Fig. 7. A part of the central vacuole of Mimosa motor cell. a: before stimulation; b: after stimulation. $\times 18000$. Both microphotographs were produced from cell materials fixed with $\mathrm{OsO}_{4}$.

was fixed in a phosphate buffer solution ( $\mathrm{pH} 7.2)$ of $1 \%$ osmium tetraoxide for 2 hours, dehydrated, and then embedded in methacryl resin by the standard procedure. Sections were examined with an electron microscope (an HS-type electron microscope of the Hitachi Company). The following results were thus obtained: In the nonstimulated material, a thin cytoplasmic layer was found along the

*) The details are exposed to be reported at the annual meeting of the Botanical Society of Japan, in Kumamoto, November, 1968. 
inside of the cell wall (Fig. 3), though a thick protoplasmic layer was sometimes observed under the same experimental conditions (Fig. 4). Diffused fine fibrous contents of the central vacuole were most clearly observable (Figs. 3 and 4). These cells probably belong to the c-type shown in the schematic figure (Fig. 2c, $\mathrm{c}^{\prime}$ ). Upon stimulation, the protoplast of the motor cell changed in shape (Figs. 5 and 6). These cells probably correspond to the c-type of Fig. 2. The electron microscopy enabled us to notice a remarkable difference in the contents of the central vacuole between the stimulated (Figs. 5, 6, and $7 \mathrm{~b}$ ) and non-stimulated material (Figs. 3, 4, and 7a). Before stimulation, diffused fine fibrils were visible; they were $20-30 \mathrm{~m} \mu$ thick and 200-400 $\mathrm{m} \mu$ long. Upon stimulation, however, the contents of the central vacuole changed in appearance, becoming aggregated fragments (Figs. 5, 6, and 7b). The biochemical nature of the fine fibrils and their morphology are expected to be studied in detail in the future.

The writers wish to express their gratitude to Dr. Masako Osumi of Japan Women's University for her assistance with the electron microscopy.

\section{References}

Toriyama, H. (1967): Distribution of tannin vacuoles in the main pulvinus of Mimosa pudica L. Proc. Japan Acad., 43, 384-388.

Toriyama, H., and Satô, S. (1968): Electron microscope observation of the motor cell of Mimosa pudica L. I. A comparison of the motor cell before and after stimulation. Proc. Japan Acad., 44, 702-706. 